\title{
Experimental Strength of Single-Lap Hybrid Joints on Woven Fabric Kenaf Fiber Composites Under Quasi Static Condition
}

\author{
Lee Sim Yee ${ }^{1, a}$ and Hilton Ahmad ${ }^{2}$ \\ ${ }^{1}$ Faculty of Civil and Environmental Engineering, Universiti Tun Hussein Onn Malaysia, 86400 Parit Raja, Johor, \\ Malaysia \\ ${ }^{2}$ Jamilus Research Center, Universiti Tun Hussein Onn Malaysia, 86400 Parit Raja, Johor, Malaysia
}

\begin{abstract}
For the past decades, usage of natural fiber reinforced composites in low bearing load applications are increasing tremendously due to drawbacks concerning the use of synthetic fibers. Kenaf fibers have a good potential to be used as composite reinforcements as they possesses excellent fiber strength compared to own self-weight. Current work concentrates on mechanical properties of woven fabric kenaf composites with single-lap hybrid joints configurations. Four width to diameter ratio, $(W / d)$ of cross-ply lay-up joints as designed in testing series were tested by using quasi static mechanical testing. Experimental results showed that the failure load increased with the increasing of W/d ratios. Thinner lay-up had better bearing strength compared to thicker lay-up as found in current study.
\end{abstract}

\section{Introduction}

Awareness in shortage of non-renewable resources is increasing greatly worldwide and concerns of implementing renewable resources are being developed by many sectors. Compared to synthetic fibers counterparts (e.g. glass fiber reinforced polymer (GFRP) and carbon fiber reinforced polymer (CFRP), natural fiber has superior properties such as higher specific strength [1], biodegradable, low carbon dioxide $\left(\mathrm{CO}_{2}\right)$ emissions, environment-friendly, good thermal and acoustic insulation. However, the mechanical properties for natural fibers vary depending on fiber types, region of origin and plantation environment.

Kenaf fiber is an important source of natural fiber as reinforcing substrate in composite materials which demonstrates good specific strength. Compression molded Kenaf-Polypropylene (PP) composites had shown greater tensile strength and flexural strength compared to other natural fibers. Kenaf-PP had lower elongation at break, thus, providing higher value of tensile strength which is about $930 \mathrm{MPa}$ [2].

Hybrid bolted-bonded joints are the combination of mechanically fastened and adhesively bonded joints. Generally, hybrid joint technique has better performance than mechanical fastening and adhesive bonded joint alone. Attaching the mechanical fastening (bolts/rivets) with adhesive bonded joint, may decrease the maximum stress near edges region which primarily decrease the peeling stresses and increase the static strength [3]. There is no standard testing method available as design

\footnotetext{
${ }^{\text {a }}$ Corresponding author : simsim1019@hotmail.com
} 
tools for hybrid joints. Thus, performance of hybrid joints are mainly influenced by the mechanical characteristic of the materials.

In recent years, there are very few available research works on hybrid joints as compared to traditional joining techniques. Fu Maofeng and Mallick [4] had studied on the effect of different washer types on static and fatigue strength for single-lap hybrid joints. Based on their study, the types and shapes of washers had direct influence upon the performance of hybrid joints, whereby the applied stress are transferred through friction due to the bolt tightening. They found that adequate clamping force on the mechanical fastening with appropriate washer type can enhance the mechanical properties of the hybrid joint. Meanwhile, Gordon Kelly [5] concluded that adhesive layer of hybrid joints are able to transfer applied remote loading. Higher load can be transferred with thicker adhesive layer through bolt friction in single-lap CFRP hybrid joint configurations. On the other hand, lesser load was transferred as the overlap length and elastic modulus were increased.

There are three dominant failure modes which occured in bolted joints which are net-tension, shear-out and bearing failures. Karakuzu et al. [6] investigated the effect of joint geometry on woven glass-vinylester composites and found that the end distance to diameter ratio $(e / d)$ for cross ply lay-up was 6 to eliminate shear-out failures with W/d ratio ranging from 2 to 5. Single-lap woven fabric CFRP bolted joints had been studied regarding the effects of joint geometry. They found that the bearing strength increases with the $W / d$ ratios [7]. However, there are still limited studies on hybrid joint, especially using natural fiber as reinforcement in composite material applications. Hence, this study is designed to investigate the effect of different $\mathrm{W} / \mathrm{d}$ ratios and laminate lay-up for single-lap hybrid bonded-bolted joint on woven fabric kenaf fiber composite plates. The current testing series were designed and experimental mechanical properties were determined by using quasi-static mechanical machines following ASTM Standard D3039B [8].

\section{Experimental Design}

\subsection{Materials}

Kenaf long fibers were used as composite reinforcement. The weaving pattern of kenaf fiber (276 tex) reinforcement was plain weave woven fabric with packing density 4 end per $\mathrm{cm}$ (in warp direction) and 4 pick per $\mathrm{cm}$ (in weft direction) as shown in Figure 1. Thermoset matrix, epoxy/hardener (SP84/SP76) was used as resin system with density of $1.14 \mathrm{~g} / \mathrm{cm}^{3}$.

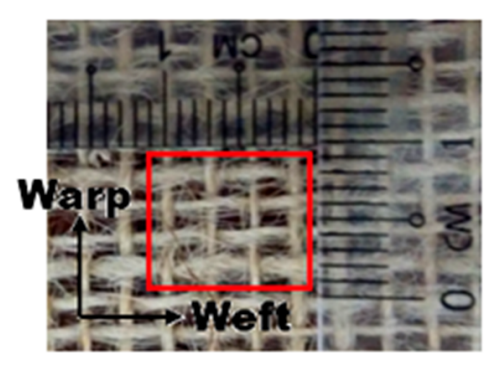

Figure 1. Density measurement for woven fabric kenaf fiber.

\subsection{Specimen preparation}

The laminates were prepared by applying one layer of resin with a ratio of $1: 2$ (hardener : epoxy) on an adjustable aluminum mold. Subsequently, a ply of plain weave (PX) woven fabric was placed on top of it, followed by another layer of resin system. The steps were repeated according to the desired laminate lay-up [PX2 $(0 / 90)_{\mathrm{s}}$ and PX4 $(0 / 90)_{2 \mathrm{~s}}$. Samples were allowed to cure for about 24 hours in a hydraulic compression machine under room temperature. The composite plates obtained were then 
sectioned according to desired sizes and a hole of $5 \mathrm{~mm}$ diameter was drilled on each specimens. Finally, fastening system with finger-tight (FT) clamping torque $(\sim 0.5 \mathrm{Nm})$ and adhesive layer (at overlap region) were applied concurrently. Single-lap kenaf fiber composite plates (FCP) geometries are illustrated in Figure 2.
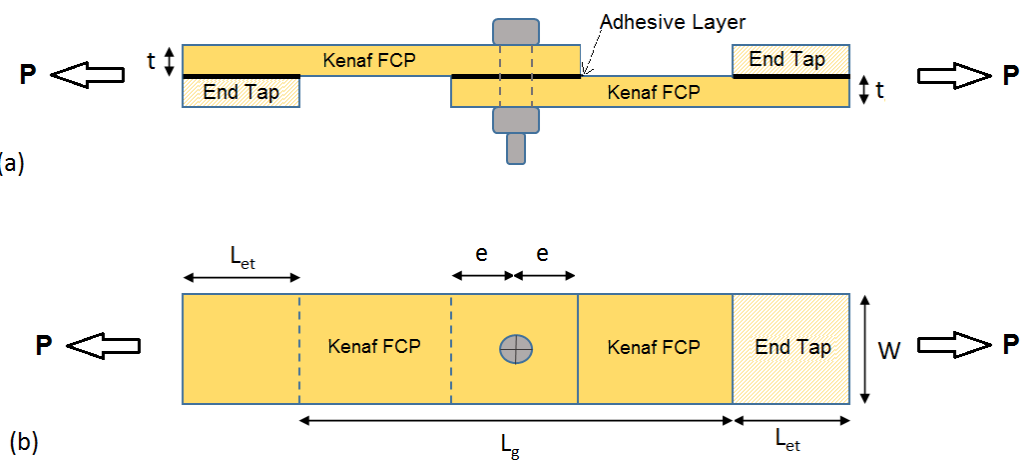

Figure 2. Single-lap hybrid joint test specimen geometry; (a) side view (b) top view.

\subsection{Tensile tests}

Tensile tests had been conducted based on ASTM Standard D3039B [8] via SHIMAZU AG-I 10kN testing machine at a constant cross-head speed of $0.5 \mathrm{~mm} / \mathrm{min}$. All testing series samples and measurements were done in triplicate as listed in Table 1 . The end-distance are kept constant $(30 \mathrm{~mm})$ and the specimens width varied according to $\mathrm{W} / \mathrm{d}$ ratios.

Table 1. Hybrid joints testing series in current study.

\begin{tabular}{|c|c|c|c|c|c|}
\hline Laminate & $\begin{array}{c}\text { Thickness, } \mathbf{t} \\
{[\mathbf{m m}]}\end{array}$ & $\boldsymbol{W} / \boldsymbol{d}$ Ratio & $\boldsymbol{e} / \boldsymbol{d}$ Ratio & $\begin{array}{c}\text { Hole Size, } \mathbf{d} \\
{[\mathbf{m m}]}\end{array}$ & $\begin{array}{c}\text { Clamp-up } \\
\text { Torques }\end{array}$ \\
\hline \multirow{4}{*}{ PX2 } & $2.15 \pm 0.01$ & 2 & 6 & 5 & FT \\
\cline { 2 - 6 } & $2.08 \pm 0.01$ & 3 & 6 & 5 & FT \\
\cline { 2 - 6 } & $2.12 \pm 0.09$ & 4 & 6 & 5 & FT \\
\cline { 2 - 6 } & $2.09 \pm 0.08$ & 5 & 6 & 5 & FT \\
\hline \multirow{5}{*}{ PX4 } & $3.62 \pm 0.01$ & 2 & 6 & 5 & FT \\
\cline { 2 - 6 } & $3.48 \pm 0.10$ & 3 & 6 & 5 & FT \\
\cline { 2 - 6 } & $3.79 \pm 0.05$ & 4 & 6 & 5 & FT \\
\cline { 2 - 6 } & $3.60 \pm 0.16$ & 5 & 6 & 5 & FT \\
\hline
\end{tabular}

\section{Results and Discussion}

This study was carried out to investigate the effect of $W / d(W / d=2,3,4,5)$ and different plate thickness (PX2 and PX4) on bearing stress at failure of woven fabric kenaf fiber composite plates under quasi-static loading. The maximum load applied, calculated bearing stress at failure and associated failure modes were determined and stated in Table 2.

Based on visual observation, both PX2 and PX4 lay-ups exhibited two types of failure mode; nettension and combination bearing/net-tension failures. Net-tension failures occurred in smaller W/d are attribute to the narrow specimen width. Meanwhile, specimens with larger $W / d$ ratio portrayed bearing/net-tension failure mode, suggesting similar failure mechanisms as reported by Smith et al. [9] that cross-ply laminates changed from delamination and splitting (full bearing failure) to laminate shear compression failure beneath the pin (due to local tensile failure). It also found that single-lap joint is susceptible to demonstrate bolt pull through and showed washer bending into testing specimen as a result of secondary bending. However, due to adhesively bonded on the shear plane may reduce 
this effect. The local failure (bearing stress) initially occurred prior to ultimately net-tension failure. Similar findings were found by Ahmad et al. [10] in woven fabric CFRP bolted joints at which intermediate $W / d$ net-tension failure was preceded by local bearing damage with unclamped condition. They also suggested full bearing failures seen to be more pronounce in quasi-isotropic lay-ups compared to cross-ply lay-ups. Figure 3 illustrates the photograph of failed PX4 specimens with different $\mathrm{W} / \mathrm{d}$ ratios.

Table 2. Maximum bearing stress at failures and associated failure modes for all testing series.

\begin{tabular}{|c|c|c|c|c|}
\hline \multirow{3}{*}{ Laminate } & $\begin{array}{c}\text { Width to } \\
\text { Diameter } \\
\text { ratio, } \boldsymbol{W} / \boldsymbol{d}\end{array}$ & $\begin{array}{c}\text { Maximum } \\
\text { Load, } \mathbf{P}_{\text {max }} \\
\mathbf{( k N )}\end{array}$ & $\begin{array}{c}\text { Maximum Bearing } \\
\text { Stress, } \boldsymbol{\sigma}_{\text {max }}(\mathbf{M P a})\end{array}$ & $\begin{array}{c}\text { Failure } \\
\text { Mode }\end{array}$ \\
\hline \multirow{3}{*}{ PX2 } & 2 & $0.78 \pm 0.01$ & $73.0 \pm 0.4$ & NT \\
\cline { 2 - 5 } & 3 & $1.30 \pm 0.04$ & $125.1 \pm 3.7$ & NT \\
\cline { 2 - 5 } & 4 & $1.58 \pm 0.11$ & $149.0 \pm 6.3$ & NT \\
\cline { 2 - 5 } & 5 & $1.90 \pm 0.14$ & $181.8 \pm 7.1$ & B-NT \\
\hline \multirow{3}{*}{ PX4 } & 2 & $0.77 \pm 0.02$ & $42.7 \pm 1.3$ & NT \\
\cline { 2 - 5 } & 3 & $1.43 \pm 0.04$ & $82.2 \pm 0.1$ & B-NT \\
\cline { 2 - 5 } & 4 & $1.65 \pm 0.05$ & $87.3 \pm 1.8$ & B-NT \\
\cline { 2 - 5 } & 5 & $1.75 \pm 0.06$ & $97.3 \pm 0.9$ & B-NT \\
\hline
\end{tabular}

*NT : Net-Tension failure

*B-NT : Bearing/Net-Tension

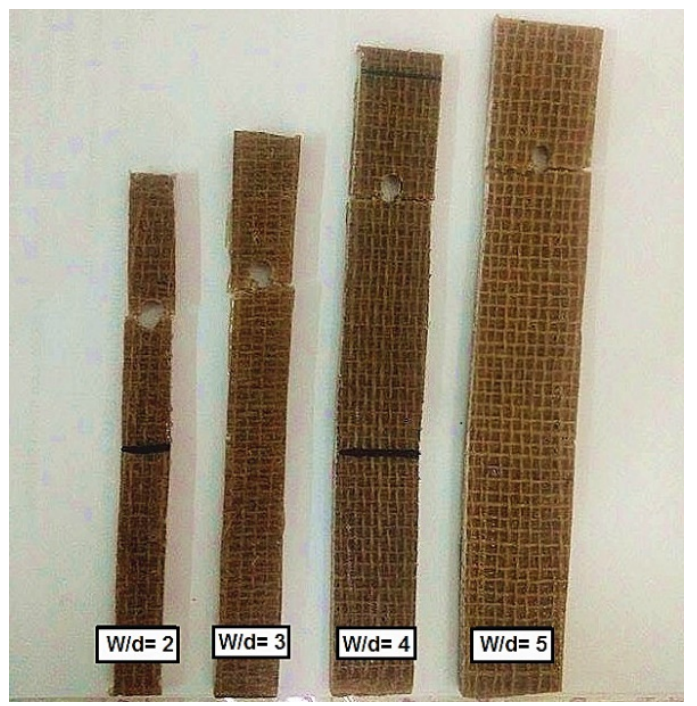

Figure 3. Failed specimens with varied $W / d$ ratio on PX4 lay-up.

The thicker specimens exhibited combined local bearing/net-tension at $W / d \geq 3$ compared with PX2 lay-up $(W / d \geq 5)$. Correspondingly, bearing strength is dependent upon plate thickness, whereby the bearing strength of PX4 is $97 \mathrm{MPa}, 50 \%$ lesser than PX2 $(182 \mathrm{MPa})$ at $W / d=5$. This is presumably due to lack of constraint through the thickness that allow the laminate expansion at unclamped condition. The strength decreased with the increase of bolted joint thickness for nettension failure. Same findings were reported by Smith et al. [9] on quasi-isotropic bolted joints. In align with previous studies [6], the bearing strength increased with the increase of $W / d$ ratio for both PX2 and PX4 specimens. Maximum bearing stresses for all lay-up understudied are shown in Figure 4 
and Table 2. Based on the graph plotted, PX4 specimens with $W / d$ ratio 3, 4 and 5 slightly increased in maximum bearing stresses which are $82.2 \mathrm{MPa}, 87.3 \mathrm{MPa}$ and $97.3 \mathrm{MPa}$, respectively. Bearing failures showed more progressive failures, therefore constant bearing stress with this failure types perhaps not surprising.

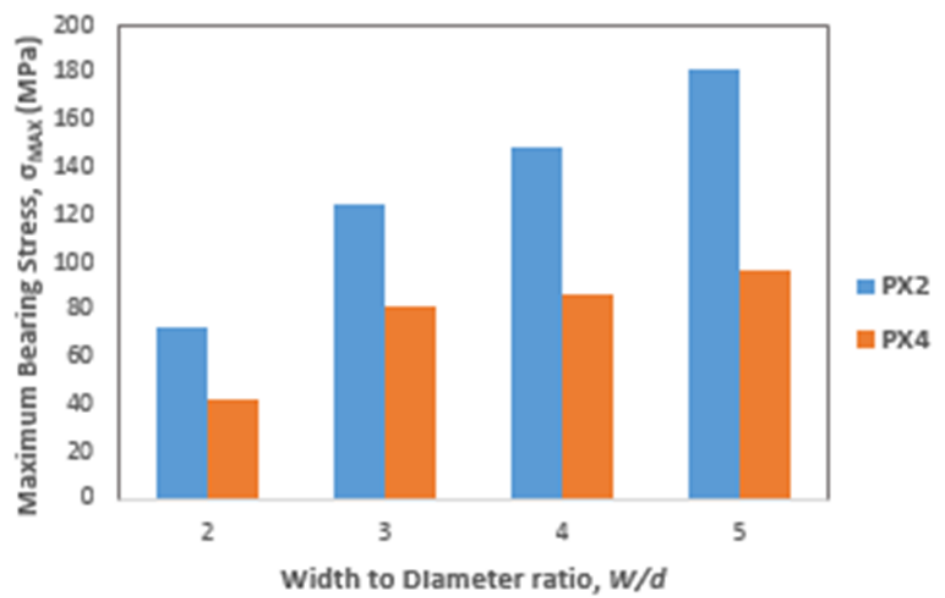

Figure 4. Effect of $W / d$ ratio on maximum bearing stress.

In current study, three testing specimens were carried out for each testing series as good reproducibility were found. Figure 5 shows the representative load-displacement curve for PX2 and PX4 with $W / d=3$. Similar load-displacement profiles were found in other $W / d$ ratios. As expected, the specimens showed that the failure loads were increased with $\mathrm{W} / \mathrm{d}$ ratios which the average maximum load for PX2 and PX4 specimens were $1.30 \mathrm{kN}$ and $1.43 \mathrm{kN}$, respectively. PX2 specimen exhibited net-tension failure mode and the curve increased gradually up to the ultimate load followed by a small load drop (almost negligible) until breaking load. It is suggested that the adhesive failed first before the joint started to slip. Crack initiated from the hole edge and propagated across the specimen width. On the other hand, the curve for PX4 specimen with bearing/net-tension failure mode was slightly displaced at some points showing more progressive behaviour but ultimately failed in nettension. However, the secondary bending does not show any significant change in load-displacement profile. The failure load showed increment trends with thicker specimens.

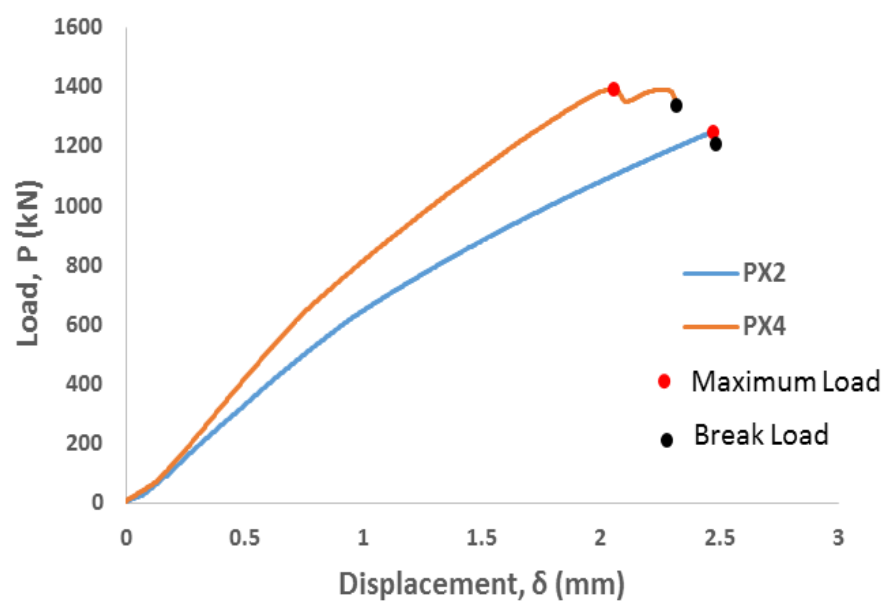

Figure 5. Load-displacement curve of hybrid joints for PX2 and PX4 lay-up with $W / d=3$. 
It is noteworthy that the current work was prepared by using hand weaving and hand lay-up techniques compared to commercially manufacturing production. Therefore, GFRP and CFRP hybrid specimens showed larger failure load than kenaf fiber hybrid specimens, i.e., in the range of $11 \mathrm{kN}$ to $16 \mathrm{kN}[11,12]$. However, kenaf fiber still provides good prospect in low bearing stress applications as mentioned previously. Although hand lay-up techniques prone to voids and porosity, current work selects the good batch of testing panels for further mechanical testing. In-depth investigations on natural fibers materials upon hybrid joints behaviour will be carried out in future.

\section{Conclusions}

The structural behaviour of single-lap hybrid bolted-bonded joints on woven fabric kenaf fiber composite plates were investigated with different lay-up types and $W / d$ ratios. Larger $W / d$ ratio and thinner specimens were found to provide greater bearing stress at failure. Failure modes in all testing series were net-tension and bearing/net-tension, where critical $W / d$ ratios were 5 and 3 for PX2 and PX4 lay-ups respectively. Further investigations on preloaded bolt joints are suggested to study the effect from clamp-up, in which increased joint strength is expected.

\section{Acknowledgements}

The authors gratefully acknowledge Universiti Tun Hussein Onn Malaysia (UTHM) and Research Grant Scheme under RAGS R034.

\section{References}

[1] H.M. Akil, M.F. Omar, A.A. M. Mazuki, S. Safiee, Z.A. M. Ishak and A. Abu Bakar, Kenaf fiber reinforced composites: A review, Mater. Des., 32. 4107-4121, (2011).

[2] O. Faruk, A.K. Bledzki, H.P. Fink and M. Sain, Biocomposites reinforced with natural fibers: 2000-2010, Prog. Polym. Sci., 37, 1552-1596, (2012)

[3] G. Marannano and B. Zuccarello, Numerical experimental analysis of hybrid double lap aluminum-CFRP joints, Compos. Part B Eng., 71, 28-39, (2015).

[4] M. Fu and P.K. Mallick, Fatigue of hybrid ( adhesive / bolted ) joints in SRIM composites, Int. J. Adhes. Adhes., 21, 145-159, (2001).

[5] G. Kelly, Load transfer in hybrid (bonded/bolted) composite single-lap joints, Compos. Struct., 69, 35-43, (2005).

[6] H. Ahmad, A.D. Crocombe, and P.A. Smith, Strength prediction in CFRP woven laminate bolted double-lap joints under quasi-static loading using XFEM, Compos. Part A Appl. Sci. Manuf., 56, 192-202, (2014).

[7] R. Karakuzu, T. Gulem and B.M. Icten, Failure analysis of woven laminated glass-vinylester composites with pin-loaded hole, Compos. Struct., 72, 27-32, (2006).

[8] ASTM D3039/D3039M, Standard Test Method for Tensile Properties of Polymer Matrix Composite Materials, ASTM International, Pennsylvania, (2008).

[9] P.A. Smith, K.J. Pascoe, C. Polak and D.O. Stroud, The behaviour of single-lap bolted joints in CFRP laminates, Composite Structures, 6, 41-55, (1986).

[10]H. Ahmad, A.D. Crocombe and P.A. Smith, Strength prediction in CFRP woven laminate bolted single-lap joints under quasi-static loading using XFEM, Compos. Part A Appl. Sci. Manuf., 66, 82-93, (2014).

[11]G. Kelly, Quasi-static strength and fatigue life of hybrid (bonded/bolted) composite single lap joints, Compos. Struct., 72, 119-129, (2006).

[12]J.S. Kim, J.Y. Lim and W.G. Lee, Joining performance evaluation of different types of GEP224 glass/epoxy-to-AZ31B magnesium alloy singlelap joints, Int. J. Precis. Eng. Man., 16, 11351140, (2015). 